\title{
Mild reductions in cytosolic NADP-dependent isocitrate dehydrogenase activity result in lower amino acid contents and pigmentation without impacting growth
}

\author{
Ronan Sulpice • Agata Sienkiewicz-Porzucek • \\ Sonia Osorio • Ina Krahnert • Mark Stitt • \\ Alisdair R. Fernie · Adriano Nunes-Nesi
}

Received: 27 February 2010/Accepted: 28 April 2010/Published online: 16 May 2010

(c) The Author(s) 2010. This article is published with open access at Springerlink.com

\begin{abstract}
Transgenic tomato (Solanum lycopersicum) plants were generated targeting the cytosolic NADPdependent isocitrate dehydrogenase gene (SlICDH1) via the RNA interference approach. The resultant transformants displayed a relatively mild reduction in the expression and activity of the target enzyme in the leaves. However, biochemical analyses revealed that the transgenic lines displayed a considerable shift in metabolism, being characterized by decreases in the levels of the TCA cycle intermediates, total amino acids, photosynthetic pigments, starch and $\mathrm{NAD}(\mathrm{P}) \mathrm{H}$. The plants showed little change in photosynthesis with the exception of a minor decrease in maximum photosynthetic efficiency $\left(F_{\mathrm{v}} / F_{\mathrm{m}}\right)$, and a small decrease in growth compared to the wild type. These results reveal that even small changes in cytosolic NADP-dependent isocitrate dehydrogenase activity lead to noticeable alterations in the activities of enzymes involved in primary nitrate assimilation and in the synthesis of 2oxoglutarate derived amino acids. These data are discussed within the context of current models for the role of the various isoforms of isocitrate dehydrogenase within plant amino acid metabolism.
\end{abstract}

Keywords Cytosolic isocitrate dehydrogenase . Solanum lycopersicum - Mitochondria · TCA cycle . Nitrogen metabolism - Amino acid biosynthesis

R. Sulpice and A. Sienkiewicz-Porzucek contributed equally to the work.

R. Sulpice · A. Sienkiewicz-Porzucek · S. Osorio ·

I. Krahnert · M. Stitt · A. R. Fernie $(\bowtie) \cdot$ A. Nunes-Nesi

Max-Planck-Institut für Molekulare Pflanzenphysiologie,

14476 Potsdam-Golm, Germany

e-mail: fernie@mpimp-golm.mpg.de

\section{Introduction}

An important role for 2-oxoglutarate (2OG) has been proposed within ammonium assimilation on the basis of studies of plants exposed to various environmental or genetic perturbations (Hodges 2002; Hodges et al. 2003; Dutilleul et al. 2005; Fritz et al. 2006; Schneidereit et al. 2006). $20 G$ is required as the primary carbon acceptor for ammonium in the GOGAT pathway. It has been proposed that this $2 \mathrm{OG}$ is either synthesized by NAD-dependent isocitrate dehydrogenase (IDH), which catalyses a tricarboxylic acid (TCA) cycle reaction wherein isocitrate is oxidized and decarboxylated to yield 2OG, NADH and $\mathrm{CO}_{2}$ (Siedow and Day 2000) or by NADP-dependent isocitrate dehydrogenase (ICDH; Chen 1998). Whilst the NAD-dependent IDH is located exclusively in the mitochondrial matrix, there are several isoforms of the NADPdependent isoforms, located in different organelles, such as the chloroplasts (Gálvez et al. 1994), mitochondria (Gálvez et al. 1998), peroxisomes (Corpas et al. 1999) and in the cytosol (Gálvez et al. 1996).

In a previous study, we evaluated the role of the mitochondrial NAD-dependent IDH by generating transgenic plants displaying mild deficiency in the expression of this gene (Sienkiewicz-Porzucek et al. 2010). These plants exhibited slight decreases in the levels of amino acids, intermediates of the TCA cycle, photosynthetic pigments, starch, and $\mathrm{NAD}(\mathrm{P}) \mathrm{H}$, increased levels of nitrate and increased total protein hinting at compensatory mechanisms to maintain $2 \mathrm{OG}$ synthesis. The vast majority of the NADP-requiring ICDH activity is due to a cytosolic isoform. This accounts for $95 \%$ of total NADP-ICDH activity in green tobacco leaf tissue, and is the predominant isoform of at least 15 species (Gallardo et al. 1995; Gálvez et al. 1996; Palomo et al. 1998; Chen, 1998). Similarly, although 
the potato cytosolic NADP-ICDH gene was active in all plant organs, its expression was highest in green tissues, flowers and roots (Fieuw et al. 1995). Chen and Gadal (1990) proposed that NADP-ICDH function in GS/GOGAT-dependent nitrogen assimilation, as a part of a cytosol-localized pathway that produces carbon skeletons for ammonium assimilation in circumstances in which TCA cycle activity is decreased. Due to the preferential expression of this isoform in mature leaf veins, NADPICDH has also been postulated to be involved in cycling, redistribution and export of amino acids, in addition to its primary function in GS/GOGAT-dependent nitrogen assimilation. It was, therefore, surprising to find that both transgenic potato (Kruse et al. 1998) and tobacco (Gálvez et al. 1999) antisense plants displaying only $6-10 \%$ residual ICDH activity showed neither growth nor developmental phenotypes. Since then, considerable research effort has been expended in an attempt to elucidate the metabolic and physiological functions of the various isoforms of isocitrate dehydrogenase (Hodges et al. 2003; Lemaitre et al. 2007). In light of the strategic positional importance of the cytosolic ICDH, studies investigating its metabolic importance in plants remain surprisingly scarce, and generally correlative in nature (Scheible et al. 2000; Bläsing et al. 2005; Urbanczyk-Wochniak et al. 2005).

As part of our ongoing project to determine the function of the TCA cycle in illuminated leaves, we have, characterized the Aco1 Solanum pennellii mutant deficient in aconitase expression (Carrari et al. 2003), as well as transgenics of cultivated tomato deficient in the expression of the mitochondrial isoforms of malate dehydrogenase (Nunes-Nesi et al. 2005), fumarase (Nunes-Nesi et al. 2007), succinyl-CoA ligase (Studart-Guimarães et al. 2007) citrate synthase (Sienkiewicz-Porzucek et al. 2008) and NAD-isocitrate dehydrogenase (SienkiewiczPorzucek et al. 2010). These studies along with those in potato tuber material in which the activity of the 2-oxoglutarate dehydrogenase complex (2OGDH) was chemically inhibited (Araújo et al. 2008), have allowed us to establish important roles for constituent enzymes of the TCA cycle in the maintenance of photosynthetic efficiency, and in the supply of carbon for amino acid biosynthesis. In this study, we turn our attention to the evaluation of the importance of the cytosolic NADPdependent isocitrate dehydrogenase for metabolism in the illuminated tomato leaf. We describe here the generation of tomato transgenic plants exhibiting mild decreases in the expression of this gene. The transgenic lines generated were characterized at transcriptional, biochemical and physiological levels. The present results are discussed in the context of current models concerning the importance of the TCA cycle and of the coordination of plant $\mathrm{CN}$ metabolism in the illuminated leaf.

\section{Results}

Transgenic NADP-dependent ICDH plants showed no change in time of flowering or growth rate

A 527-bp fragment of the tomato gene encoding SlICDH1 was cloned using the RNA interference (RNAi) design (pK7GWIWG2; Karimi et al. 2002). The RNAi construct was inserted between the cauliflower mosaic virus (CaMV) 35S promoter and the octopine synthase (ocs) terminator. Following Agrobacterium tumefaciens-mediated transformation, we transferred $25 \mathrm{ICDH}$ transformed tomato plants to the greenhouse. A first screening of the lines was performed by measuring total cellular ICDH activity (data not shown). These preliminary studies allowed the identification of two lines that showed a statistically significant and specific reduction in ICDH1 expression and total ICDH activity in leaves. These two transgenic lines were clonally propagated and transferred to the greenhouse alongside wild type controls. Following a period of 5 weeks growth, leaves were harvested in the middle of the light period, and total ICDH and NAD-dependent IDH activities were measured in order to confirm the reduced activity of NADP-dependent ICDH (Fig. 1a) and its effects on total NAD-dependent IDH activity (Fig. 1b). To verify the specificity of the constructs as well as to ensure that no compensatory effect involving increased expression of the others isoforms occurred, a secondary screen was performed at the mRNA level, using an established quantitative RT-PCR protocol (Czechowski et al. 2004). This revealed that only SIICDH1 expression was significantly reduced in the transgenic lines. Moreover, the expression of non-targeted isoforms was unaltered in the transformants (Fig. 1c). When taken together, these results demonstrate that the two lines (ICDH10 and ICDH20), are suitable for assessing the transcriptional, biochemical and physiological effects of a mild reduction of the cytosolic ICDH isoform activity.

For phenotypic characterization, we grew the transgenic plants in the greenhouse side by side with wild type controls. After 5 weeks growth no clear difference could be observed in the growth of aerial parts of the plant (data not shown). Close inspection of the transformants revealed only a slight decrease in root dry mass (Fig. 1d), stem (Fig. 1e) and leaf (Fig. 1f) biomass. From these results it follows that the transformants displayed an unaltered total biomass accumulation (Fig. 1g). This decrease was nonsignificant for line ICDH20 and only weakly significant for line ICDH10. Given that antisense inhibition of citrate synthase led to inhibition of flower formation in potato plants (Landschütze et al. 1995) and changes in fruit yield were observed in several tomato genotypes deficient in TCA cycle enzymes (Carrari et al. 2003; Nunes-Nesi et al. 


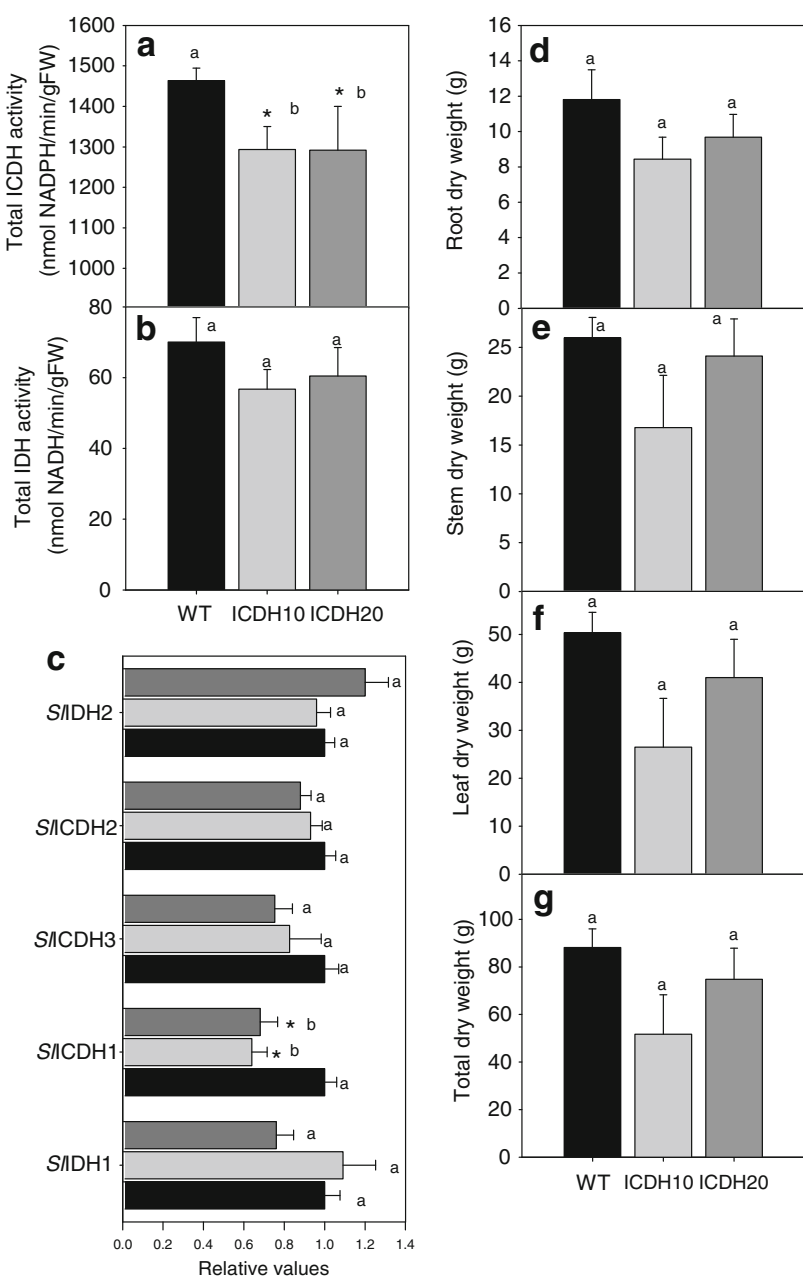

Fig. 1 Characterization and expression of tomato cytosolic isocitrate dehydrogenases. Total NADP-dependent (a) and NAD-dependent (b) isocitrate dehydrogenase activities were determined in 5-week-old leaves taken from fully expanded source leaves of transgenic plants with altered expression of SIICDH1 as compared to wild type. c The relative transcript abundance of the various cellular isoforms of isocitrate dehydrogenase. The abundance of isocitrate dehydrogenase mRNAs was measured by quantitative RT-PCR. Growth phenotype of ICDH transgenic tomato plants: $\mathbf{d}$ total root dry weight, e total stem dry weight, $\mathbf{f}$ total leaf dry weight and $\mathbf{g}$ total plant dry weight of 6weeks old plants. Values are presented as mean \pm SE $(n=5)$. An asterisk indicates significantly different values obtained for each line in comparison to wild type as determined by the $t$ test. Values marked with a different letter were determined by an ANOVA-Tukey test to be significantly different $(P<0.05)$ from each other. SlIDH1 (TC193092), SIICDH1 (TC202045); SlICDH3 mitochondrial ICDH like protein (TC196623); SlICDH2 (TC164449); SIIDH2 (TC198615). Black bar wild type, light gray bar line ICDH10, gray bar line ICDH20

2005, 2007; Studart-Guimarães et al. 2007) we next evaluated flower and fruit production in the transgenic lines. For this purpose, we grew the transgenics until full maturity counting daily the number of flowers produced. This study showed that the flowering time was not affected by the reduction in cytosolic ICDH. The total number of flowers produced by the transgenic and wild type plants were similar (data not shown), resulting in an unaltered number of fruits produced (data not shown).

Photosynthetic carbon metabolism in the cytosolic ICDH transformants

Analysis of the carbohydrate content of leaves from 5week-old plants during a diurnal cycle revealed that the transformants were characterized by unchanged levels of sucrose (Fig. 2a), glucose and fructose (data not shown), but a 30\% reduction in the level of starch (Fig. 2b).

In order to verify whether the reduction in the activity of ICDH results in changes in other major pathways of primary metabolism we used an established GC-MS protocol for metabolite profiling which allows us to quantify the relative levels of around 70 metabolites (Fernie et al. 2004). This study revealed considerable differences between the two transgenic lines and the wild type (Table 1). There were several notable changes in the contents of a range of amino acids. Namely, alanine (both lines), glutamine (both lines), arginine, asparagine, aspartate, glutamate, glycine and proline (both lines) were all significantly reduced, whilst tyramine (line ICDH10) and isoleucine (line ICDH20) were significantly increased. It is noteworthy that glutamine decreased by more than 50\%, even though $2 \mathrm{OG}$ is required to allow further metabolism of glutamine to glutamate. It is also intriguing that glutamate (which is the product of the reaction in which $2 \mathrm{OG}$ reacts with glutamine) decreased by only $20-25 \%$ whereas other amino acids showed larger decreases.

Levels of $2 \mathrm{OG}$ and isocitrate were unchanged in the transformants. This may be because interconversion of $2 \mathrm{OG}$ and isocitrate can be catalyzed by multiple isoforms of ICDH, and IDH. Despite this, other TCA cycle intermediates such as fumarate (both lines) and succinate (line ICDH10) were significantly reduced in the transformants. Several other interesting changes were also observed such as the significant reduction in threonate (line ICDH10), maleate (both lines), glycerate (line ICDH10), citramalate (line ICDH10) and an increase in pyruvate (both lines).

Reduction of cytosolic ICDH activity results in slight decreases in nitrate levels and reduced total amino acids

Given the considerable changes in amino acid metabolism we next decided to evaluate nitrate assimilation and metabolism in leaves of the transformants. For this purpose, we analyzed by spectrophotometry the content of nitrate, total amino acids and total insoluble protein in leaves. These studies revealed slight decrease in the levels of nitrate (Fig. 2c). The total amino acid levels were significantly reduced in both lines (Fig. 2d), whilst protein levels were unaltered in both lines (Fig. 2e). 
Fig. 2 Diurnal changes in sucrose (a) and starch (b) content in leaves of 6-week-old ICDH transgenic tomato plants. At each time point, samples were taken from mature source leaves, and the data presented are mean $\pm \operatorname{SE}(n=6)$. Nitrate $(\mathbf{c})$, total amino acids $(\mathbf{d})$ and protein (e) contents in leaves of ICDH transgenic tomato plants. The leaf material was harvested in the middle of the light period from 5-weekold plants. The data presented are mean \pm SE $(n=6)$. An asterisk indicates significantly different values obtained for each line in comparison to wild type as determined by the $t$ test. Values marked with a different letter were determined by an ANOVA-Tukey test to be significantly different $(P<0.05)$ from each other. The lines used were: wild type, black circles; ICDH10, gray circles; ICDH20, gray triangles. Shaded background indicates the dark period

Pigment contents in the transgenic lines

Considering the above results, we determined the levels of the photosynthetic pigments because these compounds have often been reported as important indicators of nitrogen deficiency (Gaude et al. 2007; Sienkiewicz-Porzucek et al. 2008). In accordance with our previous studies with mitochondrial citrate synthase antisense plants (Sienkiewicz-Porzucek et al. 2008), high-performance liquid chromatography (HPLC) analysis revealed a general decrease in pigment content in the transformants. Chlorophylls $a$ (both lines) and $b$ (line ICDH20) were both significantly reduced in the transformants as was lutein (line ICDH20), violaxanthin (both lines) and neoxanthin (line ICDH20), while the levels of $\beta$-carotene, zeaxanthin and antheraxanthin were unaltered (Fig. 3a).

Reduction of cytosolic ICDH activity has no effect on the relative electron transport or assimilation rates and a minor reduction in the maximum efficiency of PSII

Since we used the constitutive CaMV $35 \mathrm{~S}$ promoter to drive transgene expression in this study, we concentrated the current investigation on leaf metabolism. In addition to that, we have previously reported alterations in photosynthetic performance in tomato genotypes displaying reduced activity of aconitase (Carrari et al. 2003), mitochondrial malate dehydrogenase (Nunes-Nesi et al. 2005) and fumarase (Nunes-Nesi et al. 2007), as well as altered dark respiration in genotypes deficient in citrate synthase (Sienkiewicz-Porzucek et al. 2008). Given this, we next analyzed whether the ICDH transformants exhibited alterations in these parameters. For this purpose, we performed direct measurement of gas exchange under photon flux densities (PFD) that ranged from 0 to $1,200 \mu \mathrm{mol} \mathrm{m} \mathrm{m}^{-2} \mathrm{~s}^{-1}$. In contrast to our previous studies with lines with decreased activities of other enzymes involved in organic acid metabolism, we observed no major differences in either assimilation rate or dark respiration in the ICDH antisense lines (data not shown).
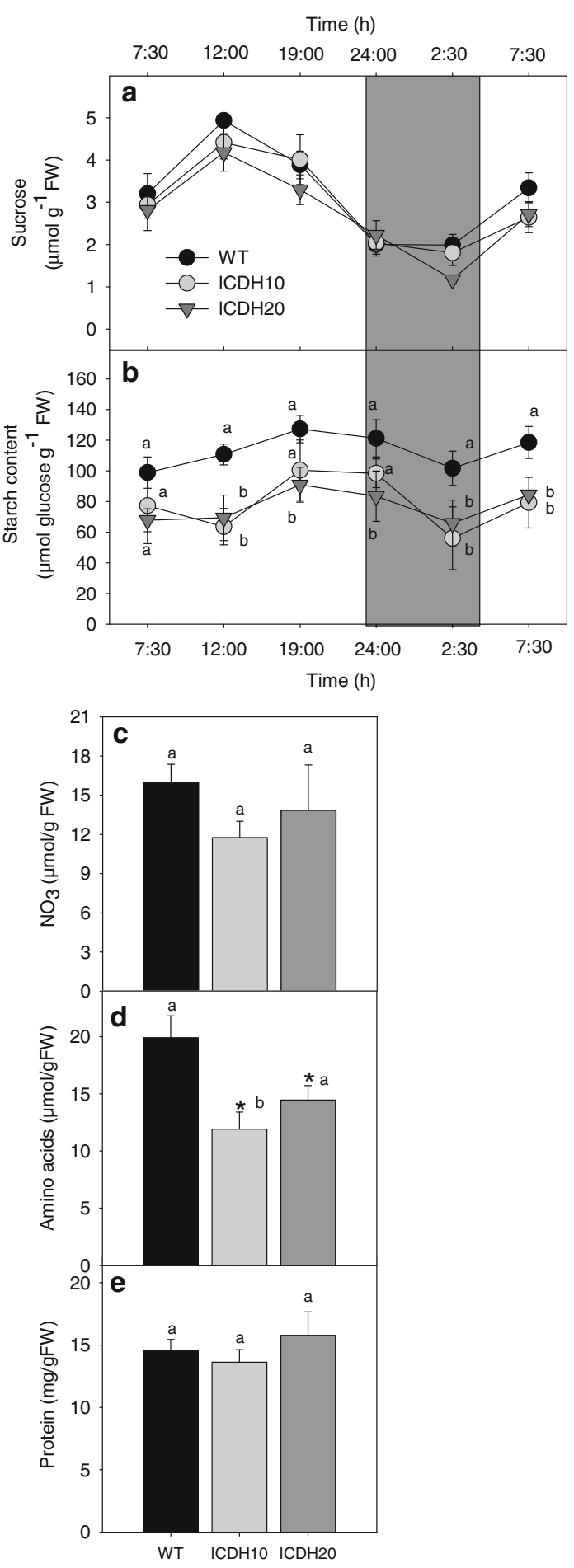

Moreover, when we measured the rate of chloroplastic electron transfer, this parameter was found to be unaltered in the transformants (data not shown). However, when we closely evaluated chlorophyll fluorescence parameters a minor but significant reduction in the PSII maximum efficiency after dark adaptation $\left(F_{\mathrm{v}} / F_{\mathrm{m}}\right)$ was observed in both lines (WT, $0.81 \pm 0.001$; ICDH10, $\mathbf{0 . 7 9} \pm \mathbf{0 . 0 0 2}$; 
Table 1 Relative metabolite content of fully expanded illuminated leaves of 5-week-old plants of the ICDH transgenic tomato plants

\begin{tabular}{|c|c|c|c|}
\hline & WT & ICDH10 & ICDH20 \\
\hline \multicolumn{4}{|l|}{ Amino acids } \\
\hline$\beta$-Alanine & $1.000 \pm 0.027 \mathrm{a}$ & $0.831 \pm 0.081 \mathrm{a}$ & $1.002 \pm 0.050 \mathrm{a}$ \\
\hline Alanine $^{\mathrm{a}}$ & $1.000 \pm 0.170 \mathrm{a}$ & $0.505 \pm 0.127 \mathrm{a}$ & $0.475 \pm 0.081 a$ \\
\hline Arginine & $1.000 \pm 0.096 \mathrm{a}$ & $0.589 \pm 0.135 b$ & $1.062 \pm 0.079 \mathrm{a}$ \\
\hline Asparagine & $1.000 \pm 0.047 \mathrm{a}$ & $0.367 \pm 0.053 b$ & $1.293 \pm 0.384 \mathrm{a}$ \\
\hline Aspartic acid & $1.000 \pm 0.048 \mathrm{a}$ & $0.361 \pm 0.055 b$ & $0.931 \pm 0.107 \mathrm{a}$ \\
\hline GABA & $1.000 \pm 0.036 \mathrm{a}$ & $1.063 \pm 0.060 \mathrm{a}$ & $0.944 \pm 0.074 a$ \\
\hline Glutamic acid & $1.000 \pm 0.024 \mathrm{a}$ & $0.798 \pm 0.059 b$ & $1.052 \pm 0.047 \mathrm{a}$ \\
\hline Glutamine & $1.000 \pm 0.152 \mathrm{a}$ & $0.421 \pm 0.139 \mathrm{~b}$ & $0.482 \pm 0.118 b$ \\
\hline Glycine & $1.000 \pm 0.063 \mathrm{a}$ & $0.496 \pm 0.083 b$ & $0.915 \pm 0.055 \mathrm{a}$ \\
\hline Isoleucine $^{\mathrm{a}}$ & $1.000 \pm 0.069 \mathrm{a}$ & $1.287 \pm 0.145 \mathrm{a}$ & $1.284 \pm 0.023 a$ \\
\hline Phenylalanine & $1.000 \pm 0.051 \mathrm{a}$ & $1.119 \pm 0.081 \mathrm{a}$ & $0.846 \pm 0.064 a$ \\
\hline Proline & $1.000 \pm 0.065 \mathrm{a}$ & $0.230 \pm 0.032 c$ & $0.533 \pm 0.070 b$ \\
\hline Serine & $1.000 \pm 0.045 \mathrm{a}$ & $0.794 \pm 0.093 \mathrm{a}$ & $1.017 \pm 0.057 \mathrm{a}$ \\
\hline Tryptophan & $1.000 \pm 0.087 \mathrm{a}$ & $1.297 \pm 0.233 a$ & $0.998 \pm 0.114 \mathrm{a}$ \\
\hline Tyramine & $1.000 \pm 0.083 a$ & $1.574 \pm 0.194 b$ & $1.015 \pm 0.070 \mathrm{a}$ \\
\hline Tyrosine & $1.000 \pm 0.058 \mathrm{a}$ & $1.349 \pm 0.189 \mathrm{a}$ & $0.961 \pm 0.081 \mathrm{a}$ \\
\hline Valine & $1.000 \pm 0.054 \mathrm{a}$ & $1.338 \pm 0.158 \mathrm{a}$ & $1.076 \pm 0.045 \mathrm{a}$ \\
\hline \multicolumn{4}{|l|}{ Organic acids } \\
\hline Citric acid & $1.000 \pm 0.059 \mathrm{a}$ & $1.053 \pm 0.048 \mathrm{a}$ & $0.928 \pm 0.068 \mathrm{a}$ \\
\hline Fumaric $\operatorname{acid}^{\mathrm{a}}$ & $1.000 \pm 0.065 \mathrm{a}$ & $0.618 \pm 0.120 b$ & $0.740 \pm 0.090 \mathrm{a}$ \\
\hline $2 \mathrm{OG}$ & $1.000 \pm 0.098 \mathrm{a}$ & $0.982 \pm 0.055 \mathrm{a}$ & $1.250 \pm 0.225 \mathrm{a}$ \\
\hline Glyceric acid & $1.000 \pm 0.063 \mathrm{a}$ & $0.712 \pm 0.040 b$ & $1.117 \pm 0.083 a$ \\
\hline Glycolic acid & $1.000 \pm 0.044 \mathrm{a}$ & $0.850 \pm 0.069 \mathrm{a}$ & $1.030 \pm 0.081 \mathrm{a}$ \\
\hline Isocitric acid & $1.000 \pm 0.051 \mathrm{a}$ & $0.868 \pm 0.054 \mathrm{a}$ & $0.847 \pm 0.154 a$ \\
\hline Lactic acid & $1.000 \pm 0.060 \mathrm{a}$ & $0.919 \pm 0.055 \mathrm{a}$ & $0.967 \pm 0.087 \mathrm{a}$ \\
\hline Maleic acid & $1.000 \pm 0.074 \mathrm{a}$ & $0.625 \pm 0.038 b$ & $0.675 \pm 0.066 b$ \\
\hline Citramalic acid & $1.000 \pm 0.046 \mathrm{a}$ & $0.739 \pm 0.048 b$ & $0.848 \pm 0.060 \mathrm{a}$ \\
\hline Malic acid & $1.000 \pm 0.022 \mathrm{a}$ & $0.935 \pm 0.037 \mathrm{a}$ & $1.007 \pm 0.057 \mathrm{a}$ \\
\hline Pyruvic acid ${ }^{a}$ & $1.000 \pm 0.067 \mathrm{a}$ & $1.485 \pm 0.104 b$ & $1.247 \pm 0.055 a$ \\
\hline Saccharic acid & $1.000 \pm 0.091 \mathrm{a}$ & $0.957 \pm 0.092 \mathrm{a}$ & $1.500 \pm 0.264 a$ \\
\hline Succinic acid & $1.000 \pm 0.080 \mathrm{a}$ & $0.746 \pm 0.075 a$ & $0.835 \pm 0.047 \mathrm{a}$ \\
\hline Threonic acid & $1.000 \pm 0.087 \mathrm{a}$ & $0.372 \pm 0.047 b$ & $0.924 \pm 0.024 a$ \\
\hline \multicolumn{4}{|l|}{ Sugars } \\
\hline Fructose & $1.000 \pm 0.036 \mathrm{a}$ & $1.057 \pm 0.039 \mathrm{a}$ & $1.060 \pm 0.063 \mathrm{a}$ \\
\hline Glucose & $1.000 \pm 0.029 \mathrm{a}$ & $0.938 \pm 0.054 \mathrm{a}$ & $1.052 \pm 0.040 \mathrm{a}$ \\
\hline Maltose $^{\mathrm{a}}$ & $1.000 \pm 0.047 \mathrm{a}$ & $0.848 \pm 0.036 a$ & $1.180 \pm 0.101 \mathrm{a}$ \\
\hline Psicose & $1.000 \pm 0.031 \mathrm{a}$ & $0.946 \pm 0.085 a$ & $0.717 \pm 0.067 b$ \\
\hline Sucrose & $1.000 \pm 0.035 \mathrm{a}$ & $1.044 \pm 0.032 \mathrm{a}$ & $1.059 \pm 0.062 \mathrm{a}$ \\
\hline Trehalose & $1.000 \pm 0.045 \mathrm{a}$ & $0.858 \pm 0.087 \mathrm{a}$ & $0.830 \pm 0.092 \mathrm{a}$ \\
\hline Xylose $^{\mathrm{a}}$ & $1.000 \pm 0.076 \mathrm{a}$ & $0.780 \pm 0.053 a$ & $0.967 \pm 0.103 a$ \\
\hline
\end{tabular}

Values set in bold type were determined by the $t$ test to be significantly different from the wild type and values marked with a different letter were determined by the ANOVA-Tukey test to be significantly different $(P<0.05)$ from each other

a Metabolite values where the significance by ANOVA-Tukey and $t$ test differed

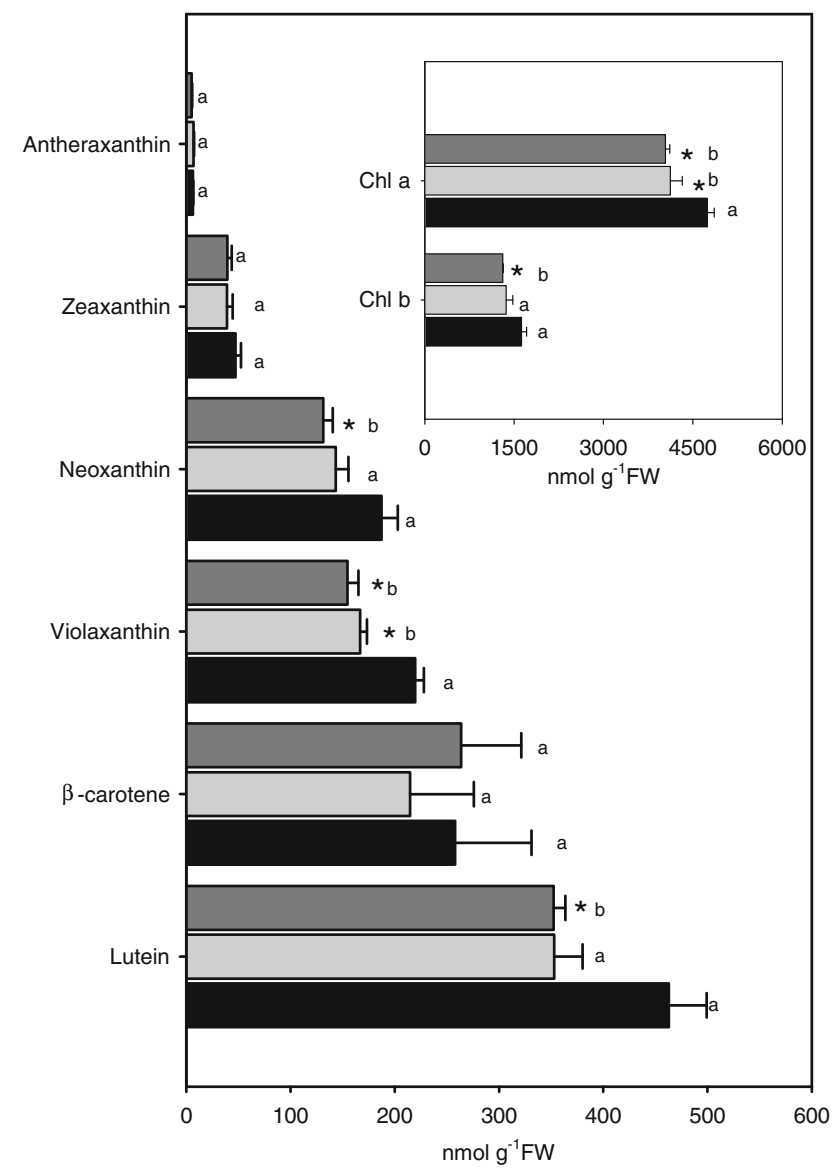

Fig. 3 Pigment content in leaves of ICDH transgenic tomato plants determined in 6-week-old fully expanded source leaves harvested in the middle of the day. Values presented are mean $\pm \mathrm{SE}$ of six individual plants per line. An asterisk indicates significantly different values obtained for each line in comparison to wild type as determined by the $t$ test. Values marked with a different letter were determined by an ANOVA-Tukey test to be significantly different $(P<0.05)$ from each other. The lines used were: wild type, black bars; ICDH10, light gray bars; ICDH20, gray bars

ICDH20, $0.79 \pm \mathbf{0 . 0 0 4}$; numbers set in bold type are significantly different from the wild type as determined by the $t$ test $P<0.05$ ).

Pyridine nucleotide content in ICDH transgenic plants

Since the oxidative decarboxylation of isocitrate to $2 \mathrm{OG}$ catalyzed by both IDH and ICDH also results in the production of reduced coenzyme $\mathrm{NAD}(\mathrm{P}) \mathrm{H}$, it might be expected that reduction in the activity of these enzymes affects the redox balance in the transformants. We therefore decided to assay the levels of pyridine dinucleotides in the leaves of wild type and transformant plants. Interestingly, there was a significant $19-33 \%$ decrease of NADH $(W T, 53.8 \pm 2.4$; ICDH10, 36.1 \pm 2.6; ICDH20, 
Table 2 Enzyme activities in ICDH transgenic lines (nmol $\left.\mathrm{min}^{-1} \mathrm{~g}^{-1} \mathrm{FW}\right)$

\begin{tabular}{|c|c|c|c|}
\hline & WT & ICDH10 & ICDH20 \\
\hline Citrate synthase & $138.41 \pm 15.18 \mathrm{a}$ & $133.38 \pm 16.17 \mathrm{a}$ & $148.92 \pm 19.78 \mathrm{a}$ \\
\hline Aconitase & $351.34 \pm 40.94 \mathrm{a}$ & $334.80 \mathrm{a} \pm 58.79 \mathrm{a}$ & $464.59 \pm 71.03 \mathrm{a}$ \\
\hline GDH (NAD) & $226.60 \pm 25.16 a$ & $289.35 \pm 18.06 \mathrm{a}$ & $327.94 \pm 13.82 b$ \\
\hline Nitrate reductase & $321.05 \pm 32.76 \mathrm{a}$ & $351.73 \pm 48.42 \mathrm{a}$ & $368.18 \pm 33.05 \mathrm{a}$ \\
\hline Pyruvate kinase & $1,108.64 \pm 94.20 \mathrm{a}$ & $897.31 \pm 132.58 \mathrm{a}$ & $1,211.20 \pm 83.26 \mathrm{a}$ \\
\hline PEP Carboxylase & $1,432.68 \pm 96.30 \mathrm{a}$ & $1,086.12 \pm 160.94 \mathrm{a}$ & $1,390.21 \pm 111.76 \mathrm{a}$ \\
\hline Fumarase & $5,121.71 \pm 853.18 \mathrm{a}$ & $2,646.24 \pm 483.53 b$ & $3,400.07 \pm 350.61 \mathrm{a}$ \\
\hline Glycerate kinase & $1,963.57 \pm 135.33 \mathrm{a}$ & $2,175.45 \pm 180.81 \mathrm{a}$ & $2,226.96 \pm 200.21 \mathrm{a}$ \\
\hline MDH (NAD) & $75,304.24 \pm 4,558.54 \mathrm{a}$ & $81,992.53 \pm 5,414.97 \mathrm{a}$ & $73,068.12 \pm 4,914.24 \mathrm{a}$ \\
\hline MDH total (NADP) & $5,464.99 \pm 184.15 \mathrm{a}$ & $4,483.07 \pm 186.77 b$ & $5,167.04 \pm 245.29 \mathrm{a}$ \\
\hline MDH initial (NADP) & $795.72 \pm 26.40 \mathrm{a}$ & $657.85 \pm 19.51 b$ & $703.25 \pm 17.74 b$ \\
\hline MDH activation ${ }^{\mathrm{a}}$ & $0.146 \pm 0.003 \mathrm{a}$ & $0.148 \pm 0.007 \mathrm{a}$ & $0.137 \pm 0.007 \mathrm{a}$ \\
\hline
\end{tabular}

Activities were determined in 5-week-old fully expanded source leaves harvested $6 \mathrm{~h}$ into the photoperiod. Data presented are mean $\pm \mathrm{SE}$ of measurements from six independent plants per genotype. Values set in bold type were determined by the $t$ test to be significantly different from the wild type and values marked with a different letter were determined by the ANOVA-Tukey test to be significantly different $(P<0.05)$ from each other

FW Fresh weight, $P E P$ phosphoenolpyruvate, $M D H$ malate dehydrogenase, $G D H$ glutamate dehydrogenase

${ }^{\text {a }}$ Ratio of initial NADP-MDH activity to total NADP-MDH activity

43.6 $\pm 3.5 \mathrm{nmol} \mathrm{NADH} / \mathrm{gFW}$; numbers set in bold type are significantly different from the wild type as determined by the $t$ test $P<0.05)$ in the transgenic lines. There was also a significant, but much smaller, decrease of NADPH (WT, $26.6 \pm 0.9 ; \quad$ ICDH10, $\quad \mathbf{2 3 . 5} \pm \mathbf{0 . 9} ; \quad$ ICDH20, $22.4 \pm$ $1.4 \mathrm{nmol} \mathrm{NADPH} / \mathrm{gFW}$; numbers set in bold type are significantly different from the wild type as determined by the $t$ test $P<0.05$ ), NAD and NADP levels were essentially unaltered in all genotypes (data not shown). As a result, a decrease in the NADH/NAD (WT, $1.18 \pm 0.11$; ICDH10, 0.64 $\pm \mathbf{0 . 0 5}$; ICDH20, 0.77 $\pm \mathbf{0 . 0 6}$; numbers set in bold type are significantly different from the wild type as determined by the $t$ test $P<0.05$ ) and unaltered NADPH/ NADP ratios was observed (WT, $0.50 \pm 0.04$; ICDH10, $0.51 \pm 0.04 ; \mathrm{ICDH} 20,0.51 \pm 0.08)$.

Effect of reduction of cytosolic ICDH on the activities of other enzymes of primary metabolism

To better understand the above described changes in metabolites, we next analyzed the maximal activities of a wide range of key enzymes of carbon and nitrogen metabolism (Table 2). Our previous results on the mitochondrial isocitrate dehydrogenase suggested a reduced capacity for nitrate assimilation in the IDH lines (Sienkiewicz-Porzucek et al. 2010). As seen previously for IDH, NAD-dependent glutamate dehydrogenase (GDH) activity was significantly increased (line ICDH20), suggesting that glutamate might be oxidized in the mitochondria in order to sustain the supply of $2 \mathrm{OG}$ to the TCA cycle, concomitant to the release of $\mathrm{NH}_{4}{ }^{+}$(Robinson et al. 1991; Aubert et al. 2001). We also assayed glycerate kinase, which is a key enzyme of the photorespiratory cycle (Boldt et al. 2005). This enzyme was only slightly increased in both transgenic lines. Considering TCA cycle enzymes, there were no significant differences in the total activities of citrate synthase, aconitase and NAD-dependent malate dehydrogenase. However, the activity of fumarase was reduced (significantly in line ICDH10). As described before, both transgenics lines showed lower NAD $(\mathrm{P}) \mathrm{H}$ levels, reduced pigment levels and minor reduction in the efficiency of PSII. For that reason we expected changes in the chloroplastic redox state (Scheibe 2004). To further test this hypothesis, we assayed both initial and maximal activities of NADP-dependent malate dehydrogenase and from these data calculated the activation state of the enzyme. The results revealed that both total and initial NADP-MDH activities were reduced in the both ICDH lines, however, no change in the activation state of NADPMDH was observed.

\section{Discussion}

Much research effort has been recently invested in the study of plant photosynthetic energy metabolism in order to better understand the functional role of respiratory metabolism in the illuminated leaf. Studies in which components of the mitochondrial electron transport chain were manipulated indicate that its correct functioning is required to sustain optimal rates of photosynthesis (Igamberdiev et al. 2001; Dutilleul et al. 2003; 2005; Bartoli 
et al. 2005; Sweetlove et al. 2006). A similar conclusion has been reached in pharmacological approaches (Raghavendra and Padmasree 2003). Mitochondria ATP synthesis contributes to maintenance of the ATP/ADP ratio in the cytosol in the light, at least under photorespiratory conditions (Wigge et al. 1993; Igamberdiev and Gardeström 2003). In the current article, we focussed our effort on understanding the influence of NADP-dependent isocitrate dehydrogenase on photosynthetic metabolism. Inhibition of the cytosolic NADP-dependent isocitrate dehydrogenase resulted in unaltered rate of assimilation and chloroplastic electron transport, but the maximal efficiency of photosystem II $\left(F_{\mathrm{v}} / F_{\mathrm{m}}\right)$ was slightly reduced in the transformants. Consistent with this alteration are the changes observed in pigment content such as the reduction in chlorophyll $a$ and $b$, violaxanthin, zeaxanthin and lutein (Fig. 3). There are two possible explanations for the reduced levels of pigments. They could reflect the reduced rate of nitrate assimilation and thus reduced supply of precursors, such a hypothesis is supported by the metabolic profiling of these plants which shows large reductions in organic acids and the amino acid pools which they support (Table 1). Alternatively, they could be caused by the altered redox balance of the transgenics, given that their biosynthesis is subject to redox-regulated control (Isaacson et al. 2004).

Despite these rather minor changes in photosynthesis, considerable changes were observed in metabolism. One of the most striking effects was a general decrease in starch accumulation (Fig. 2). It is already well known that diurnal changes in starch as well as organic acid biosynthesis are synchronized to nitrate assimilation (Scheible et al. 1997; Chia et al. 2000; Scheible et al. 2000). Downregulation of the cytosolic ICDH also led to a decrease in total amino acid levels, decrease in fumarate and succinate, increased pyruvate, but did not affect nitrate levels or protein levels (Fig. 2). Many of these changes are similar to those observed following inhibition of the mitochondrial citrate synthase (Sienkiewicz-Porzucek et al. 2008). Interestingly, there are similarities and differences to the response in tomato plants with decreased expression of the mitochondrial NAD-dependent IDH (Sienkiewicz-Porzucek et al. 2010), which in effect catalyses a redundant reaction with respect to $2 \mathrm{OG}$ formation, except that the reaction occurs in a different compartment and with a different redox couple. In both cases, a small decrease in activity led to lower starch content, decreased NADH and NADPH, a decreased NADH/NAD ratio, a marked decrease in fumarase activity, and a trend to higher GDH activity. However, whereas a decrease in IDH activity had little effect on the total amino acid content and the levels of most of the individual amino acids, and resulted in an increased nitrate and protein content, a decrease in ICDH activity led to a
$50 \%$ decrease of the total amino acid content, decreased levels of many of the individual amino acids, a lower nitrate content and an unaltered protein content. Moreover, unlike the situation observed in the mitochondrial NADdependent isocitrate dehydrogenase antisense lines there was no effect on the activity of nitrate reductase.

Despite the importance of $20 \mathrm{O}$ in respiration, photorespiration and nitrogen metabolism, it is not yet clear where the major site of production of $20 \mathrm{O}$ resides. This organic acid can in principle either be produced from sugar respiration or by amino acid transamination, following the concerted action of isocitrate dehydrogenases, aminotransaminases and GDH (Lancien et al. 2000). When the current results are taken alongside those of our previous study (Sienkiewicz-Porzucek et al. 2010), it can clearly be stated that both the mitochondrial NAD-dependent isocitrate dehydrogenase and the cytosolic NADP-dependent isocitrate dehydrogenase appear to have an important role in $20 \mathrm{O}$ production in the light. The lines described in the present study displayed a small yet specific significant reduction of the cytosolic NADP-dependent isocitrate dehydrogenase activity, without any effect on the mitochondrial NAD-dependent isocitrate dehydrogenase activity. This did not result in reduction of absolute $20 \mathrm{O}$ levels. However, there were clear reductions in the levels of the amino acids alanine, glutamine and proline, a smaller decrease in glutamate, and decreases of many other amino acids. A small reduction in IDH activity also had no marked effect on $20 \mathrm{OG}$ levels, but led to a decrease of proline, glycerate and smaller changes of other organic acids (Sienkiewicz-Porzucek et al. 2010). The minimal change in the level of $20 \mathrm{O}$ in these genetic perturbations is in agreement with previous studies, which have shown that 2OG levels are remarkably constant across a wide range of treatments (Fritz et al. 2006 and refs therein). These results indicate that the $2 \mathrm{OG}$ level is tightly controlled, and that decreases in synthesis via one pathway may be compensated by increased synthesis via another pathway.

Two features in the data of the present study and Sienkiewicz-Porzucek et al. (2010) are worthy of note with respect to mechanisms that may compensate for decreased expression of cytosolic ICDH or mitochondrial IDH. Firstly, it is interesting that the RNAi cytosolic NADPdependent isocitrate dehydrogenase lines and the antisense mitochondrial NAD-dependent isocitrate dehydrogenase lines display elevated levels of GDH. Under the perception of nitrogen-limiting conditions, this enzyme might provide glutamate and maintain nitrogen metabolism (Tercé-Laforgue et al. 2004). Evidence for such a compensatory mechanism has been provided by antisense inhibition of ferredoxin-dependent glutamine-2-oxoglutarate aminotransferase (Fd-GOGAT) tobacco plants (Ferrario-Mery et al. 2002). Secondly, the RNAi cytosolic ICDH lines and 
the antisense mitochondrial IDH lines show decreased levels of NADH and NADPH, and a decreased NADH/ NAD ratio. It has been proposed that a high ATP or, more probably, a high redox state may restrict the synthesis of 2OG, based on studies of a $N$. sylvestris cms mutant in which mitochondrial complex I is impaired (Dutilleul et al. 2003, 2005), and a meta-analysis of $20 \mathrm{O}$ and glutamate levels in low and high light in wild type tobacco and $r b c s$ antisense lines (Fritz et al. 2006). In this case, the decrease in the NADH/NAD and NADPH/NADP ratios in the antisense IDH and RNAi ICDH lines might be part of a compensatory response to maintain 2OG synthesis. Thus, the cytosolic ICDH is involved in the regulation of pyridine dinucleotide, isocitrate and 2OG (Igamberdiev and Gardeström 2003). The deficiency of the cytosolic NADPdependent isocitrate dehydrogenase clearly results in an alteration of not only the total cellular redox balance but also, as indicated by the activities of the chloroplastic malate dehydrogenase, of the subcellular redox poise. However, whilst these alterations are likely, at least partially, responsible for the large metabolic shifts observed in these plants they have little effect on plant performance or fertility.

Recently, Pracharoenwattana et al. (2010) recently showed that cytosolic fumarase (FUM2) accounts for most of the total fumarase activity in Arabidopsis, and that fum2 knock-out lines have decreased levels of fumarate, lower levels of amino acids in the light, and impaired growth on high nitrogen. Intriguingly, the RNAi cytosolic ICDH lines and the antisense mitochondrial IDH lines showed a 33-50 and $>50 \%$ decrease in fumarase activity, respectively, and the ICDH lines had significantly lower levels of fumarate. These results add to the evidence for a close link between fumarate accumulation and nitrogen assimilation.

To summarize, in this article, we have demonstrated that minor changes in activity of cytosolic NADP-isocitrate dehydrogenase in tomato leaves has dramatic metabolic consequences but these have little effect on growth or plant performance. Despite this fact, this study allows several important conclusions to be made. It demonstrates that both the mitochondrial NAD-dependent isocitrate dehydrogenase and the cytosolic NADP-dependent isocitrate dehydrogenase have important and partly non-redundant roles in nitrate assimilation. Furthermore, it suggests the operation of compensatory mechanisms to maintain $20 \mathrm{O}$ production which underlines the importance of this metabolite for maintenance of normal cellular function. It is clear that a mild reduction in the cytosolic NADP-dependent isocitrate dehydrogenase led to a slow-down of the TCA cycle, and consequently a likely reduction in the mitochondrial levels of NADH and NADPH. When assessed in the context of studies of the TCA cycle in general the fact that antisense lines of different enzymes of the cycle have dramatically different phenotypes is highly interesting. When considered together alongside recent genome scale models of Arabidopsis metabolism (Poolman et al. 2009; de Oliveira Dal'Molin et al. 2010) and the lack of congruence between the expression levels (Urbanczyk-Wochniak et al. 2005) and maximum catalytic activities of the constituent enzymes (Gibon et al. 2004), gives strong support for the contention that, as in bacteria, the TCA cycle of plants operates in a modular manner (Sweetlove et al. 2010; Gauthier et al. 2010; Tcherkez et al. 2009). Within such a context it is clear from our work that citrate synthase, the mitochondrial NAD-dependent isocitrate dehydrogenase, the cytosolic NADP-dependent isocitrate dehydrogenase and perhaps also $20 \mathrm{O}$ dehydrogenase would form such a functional module within the illuminated leaf with responsibility for the provision of the precursors for amino acid biosynthesis during nitrate assimilation.

\section{Methods}

\section{Materials}

Tomato (Solanum lycopersicum) 'Moneymaker' was obtained from Meyer Beck. Plants were handled as described in the literature (Carrari et al. 2003). All chemicals and enzymes used in this study were obtained from Sigma and Roche Diagnostics.

\section{cDNA cloning and expression}

A 527-bp fragment of the cytosolic SIICDH1 was cloned using the RNAi design (pK7GWIWG2; Karimi et al. 2002) between the CaMV 35S promoter and the ocs terminator into the vector pBINAR (Liu et al. 1999). These constructs were introduced into plants by an Agrobacterium-mediated transformation protocol, and plants were selected and maintained as described in the literature (Tauberger et al. 2000). Initial screening of 25 lines was carried out on the basis of total enzyme activity determinations. These screens allowed the selection of two lines, which were taken to the next generation. Total IDH and ICDH activity and expression of the various isoforms of IDH and ICDH were confirmed in the second harvest of these lines.

RNA extraction and quantification and qRT-PCR analysis

The RNA and qRT-PCR were determined as described in Zanor et al. (2009). Relative quantification of the target expression of IDH and ICDH genes in WT and transgenic lines was performed using the comparative $\mathrm{Ct}$ method. For 
analysis of SlIDH1 transcript levels (GenBank accession no. TC163092), the following primers, forward $5^{\prime}$-CAGT GAAGCGTGTTATTGCCG- ${ }^{\prime}$, reverse $5^{\prime}$-GACAGCATC CGTGATTTCTTGG-3', and SIICDH1 (GenBank accession no. TC202045), forward 5'-TCCTGATGGCAAGAC CATTGA- $3^{\prime}$, reverse $5^{\prime}$-TGTGCTGGTT TCACCTCCT TTC-3', for SlICDH3 (GenBank accession no. TC196623), forward 5'-ATGCACGAACATTCCCAGGA-3', reverse 5'-TGGCACGATACTGATCACCAAA-3', for SlICDH2 (GenBank accession no. TC164449), forward $5^{\prime}$-GA AGCAGCCCATGGAACTGTT- $3^{\prime}$, reverse 5'-TCCAC GAGTCCAAGCAAAAATC- ${ }^{\prime}$, and for SlIDH2 (GenBank accession no. TC198615) forward 5'-CTTTGAGCGA TACGAAGTGCG-3', reverse 5'-GCCCTCCTTTCAGA CAAACCTT- $3^{\prime}$. To normalize genes expression for differences in the efficiency of cDNA synthesis, transcript levels of the constitutively expressed elongation factor 1- $\alpha$ of S. lycopersicum (GenBank accession no. X14449) and ubiquitin3 (GenBank accession no. X58253) were measured using the following primers, forward, $5^{\prime}$-ACC ACG AAG CTC TCC AGG AG-3', reverse, 5'-CAT TGA ACC CAA CAT TGT CAC C-3' ${ }^{\prime}$, Schaarschmidt et al. (2006) for elongation factor $1-\alpha$ and forward, 5'-AGGTTGATGA CACTGGAAAGGTT-3', reverse, 5'-ATCGCCTCCAG CCTTGTTGTA-3' for ubiquitin3 (Wang et al. 2008).

\section{Analysis of enzyme activities}

Enzyme extracts were prepared as described previously (Gibon et al. 2004), except that Triton-X 100 was used at a concentration of $1 \%$ and glycerol at $20 \%$. Citrate synthase, isocitrate dehydrogenase (NAD), phosphofructokinase (ATP) fumarase and pyruvate kinase were assayed as described in Nunes-Nesi et al. (2007). Malate dehydrogenase (NADP) was assayed as described in Scheibe and Stitt (1988). NADP-isocitrate dehydrogenase, nitrate reductase, PEPC and GDH (NAD) were assayed as described in Gibon et al. (2004). Glycerate kinase was assayed as described in Huege et al. (2007).

\section{Determination of metabolite levels}

Leaf samples were taken at the time point indicated, immediately frozen in liquid nitrogen, and stored at $-80^{\circ} \mathrm{C}$ until further analysis. Extraction was performed by rapid grinding of tissue in liquid nitrogen and immediate addition of the appropriate extraction buffer. The levels of starch, sucrose, fructose, and glucose in the leaf tissue were determined exactly as described previously (Fernie et al. 2001). The levels of all other metabolites were quantified by GC-MS exactly following the protocol described by Roessner et al. (2001) with the exception that peak identification was optimized to tomato tissues (Roessner-Tunali et al. 2003) and extended to include newly identified peaks (Kopka et al. 2005; Schauer et al. 2005). Nitrate was determined as detailed in Fritz et al. (2006). The procedure of extraction and assay of NAD, NADH, NADP and NAPH was performed according to the method described by Gibon and Larher (1997). Photosynthetic pigments were determined exactly as described in Bender-Machado et al. (2004).

Measurements of photosynthetic parameters

Four to 5-week-old plants maintained at fixed irradiance of $250 \mu \mathrm{mol}$ photons $\mathrm{m}^{-2} \mathrm{~s}^{-1}$ were used for gas exchange using a Licor-6400 gas exchange system (Li-Cor; http://www.licor.com/) under different light intensities (as described in the text), $400 \mathrm{ppm} \mathrm{CO}_{2}$, and a leaf temperature of $25^{\circ} \mathrm{C}$. Fluorescence emission measurements to estimate the actual flux of photons driving photosystem II (ETR) was performed using a leaf chamber fluorometer (Model 6400-40, Li-Cor).

Statistical analysis

The $t$ tests were performed using the algorithm embedded into Microsoft Excel (Microsoft) and analysis of variance and ANOVA-Tukey test were performed using the $\mathrm{R}$ software (R Development Core Team 2006). The term significant is used in the text only when the change in question has been confirmed to be significant by the $t$ test $(P<0.05)$ in order to aid comparison to previous studies of TCA cycle transgenics. However, results from the ANOVA-Tukey test are superimposed on the data.

Acknowledgments We are indebted to Anna Zbierzak (MaxPlanck-Institut für Molekulare Pflanzenphysiologie) for pigment measurements and to Beatrice Encke and Nicole Krohn for spectrophotometric assays of metabolites. In addition, we acknowledge the excellent care of the plants by Helga Kulka (Max-Planck-Institut für Molekulare Pflanzenphysiologie).

Open Access This article is distributed under the terms of the Creative Commons Attribution Noncommercial License which permits any noncommercial use, distribution, and reproduction in any medium, provided the original author(s) and source are credited.

\section{References}

Araújo WL, Nunes-Nesi A, Trenkamp S, Bunik VI, Fernie AR (2008) Inhibition of 2-oxoglutarate dehydrogenase in potato tuber suggests the enzyme is limiting for respiration and confirms its importance in nitrogen assimilation. Plant Physiol 148:17821796

Aubert S, Bligny R, Douce R, Gout E, Ratcliffe RG, Roberts JKM (2001) Contribution of glutamate dehydrogenase to mitochondrial glutamate metabolism studied by ${ }^{13} \mathrm{C}$ and ${ }^{31} \mathrm{P}$ nuclear magnetic resonance. J Exp Bot 52:37-45 
Bartoli CG, Gomez F, Gergoff G, Guiamet JJ, Puntarulo S (2005) Upregulation of the mitochondrial alternative oxidase pathway enhances photosynthetic electron transport under drought conditions. J Exp Bot 56:1269-1276

Bender-Machado L, Bauerlein M, Carrari F, Schauer N, Lytovchenko A, Gibon Y, Kelly AA, Ehlers-Loureiro M, MullerRober B, Willmitzer L, Fernie AR (2004) Expression of a yeast acetyl CoA hydrolase in the mitochondrion of tobacco plants inhibits growth and restricts photosynthesis. Plant Mol Biol 55:645-662

Bläsing O, Gibon Y, Günther M, Höhne M, Osuna D, Thimm T, Scheible W-R, Morcuende R, Stitt M (2005) Sugars and circadian regulation make major contributions to the global regulation of diurnal gene expression in Arabidopsis. Plant Cell 17:3257-3281

Boldt R, Edner C, Kolukisaoglu Ü, Hagemann M, Weckwerth W, Wienkoop S, Morgenthal K, Bauwe H (2005) D-Glycerate 3kinase, the last unknown enzyme in the photorespiratory cycle in Arabidopsis, belongs to a novel kinase family. Plant Cell 17:2413-2420

Carrari F, Nunes-Nesi A, Gibon Y, Lytovchenko A, Ehlers-Loureiro M, Fernie AR (2003) Reduced expression of aconitase results in an enhanced rate of photosynthesis and marked shifts in carbon partitioning in illuminated leaves of wild species tomato. Plant Physiol 133:1322-1335

Chen R (1998) Plant NADP-dependent isocitrate dehydrogenases are predominantly localized in the cytosol. Planta 207:280-285

Chen RD, Gadal P (1990) Do the mitochondria provide the 2oxoglutarate needed for glutamate synthesis in higher plant chloroplasts? Plant Physiol Biochem 28:141-145

Chia DW, Yoder TJ, Reiter WD, Gibson SI (2000) Fumaric acid: an overlooked form of fixed carbon in Arabidopsis and other plant species. Planta 211:743-751

Corpas FJ, Barroso JB, Sandalio LM, Palma JM, Lupianez JA, del Rio LA (1999) Peroxisomal NADP-dependent isocitrate dehydrogenase. Characterization and activity regulation during natural senescence. Plant Physiol 121:921-928

Czechowski T, Bari RP, Stitt M, Scheible WR, Udvardi MK (2004) Real-time RT-sensitivity reveals novel root- and shoot-specific genes. Plant J 38:366-379

de Oliveira Dal'Molin CG, Quek LE, Palfreyman RW, Brumbley SM, Nielsen LK (2010) AraGEM, a genome-scale reconstruction of the primary metabolic network in Arabidopsis. Plant Physiol 152:579-589

Dutilleul C, Driscoll S, Cornic G, De Paepe R, Foyer CH, Noctor G (2003) Functional mitochondrial complex $\mathrm{I}$ is required for optimal photosynthetic performance in photorespiratory conditions and during transients. Plant Physiol 131:264-275

Dutilleul C, Lelarge C, Prioul JL, De Paepe R, Foyer CH, Noctor G (2005) Mitochondria-driven changes in leaf NAD status exert a crucial influence on the control of nitrate assimilation and the integration of carbon and nitrogen metabolism. Plant Physiol 139:64-78

Fernie AR, Roscher A, Ratcliffe RG, Kruger NJ (2001) Fructose 2,6bisphosphate activates pyrophosphate: fructose 6 phosphate 1 phosphotransferase and increases triose phosphate to hexose phosphate cycling in heterotrophic cells. Planta 212:250-263

Fernie AR, Carrari F, Sweetlove LJ (2004) Respiratory metabolism: glycolysis, the TCA cycle and mitochondrial electron transport chain. Curr Opin Plant Biol 7:254-261

Ferrario-Mery S, Hodges M, Hirel B, Foyer CH (2002) Photorespiration-dependent increases in phosphoenolpyruvate carboxylase, isocitrate dehydrogenase and glutamate dehydrogenase in transformed tobacco plants deficient in ferredoxin-dependent glutamine-a-ketoglutarate aminotransferase. Planta 214:877-886
Fieuw S, Müller-Röber B, Gálvez S, Willmitzer L (1995) Cloning and expression analysis of the cytosolic $\mathrm{NADP}^{+}$-dependent isocitrate dehydrogenase from potato. Plant Physiol 107:905-913

Fritz C, Palacios-Rojas N, Feil R, Stitt M (2006) Regulation of secondary metabolism by the carbon-nitrogen status in tobacco: nitrate inhibits large sectors of phenylpropanoid metabolism. Plant J 46:533-548

Gallardo F, Gálvez S, Gadal P, Canovas FM (1995) Changes in NADP+-linked isocitrate dehydrogenase during tomato fruit ripening. Planta 196:148-154

Gálvez S, Bismuth E, Sarda C, Gadal P (1994) Purification and characterization of chloroplast NADP-isocitrate dehydrogenase from mixotrophic tobacco cells: comparison with the cytosolic isoenzyme. Plant Physiol 105:593-600

Gálvez S, Hodges M, Decottignies P, Bismuth E, Lancien M, Sangwan RS, Dubois F, LeMaréchal P, Cretin C, Gadal P (1996) Identification of a tobacco cDNA encoding a cytosolic NADPisocitrate dehydrogenase. Plant Mol Biol 30:307-320

Gálvez S, Roche O, Bismuth E, Brown S, Gadal P, Hodges M (1998) Mitochondrial localization of a NADP-dependent isocitrate dehydrogenase isoenzyme by using the green fluorescent protein as a marker. Proc Natl Acad Sci USA 95:7813-7818

Gálvez S, Lancien M, Hodges M (1999) Are isocitrate dehydrogenases and 2-oxoglutarate involved in the regulation of glutamate synthesis? Trends Plant Sci 4:484-490

Gaude N, Brehelin C, Tischendorf G, Kessler F, Dormann P (2007) Nitrogen deficiency in Arabidopsis affects galactolipid composition and gene expression and results in accumulation of fatty acid phytyl esters. Plant J 49:729-739

Gauthier PPG, Bligny R, Gout E, Mahé A, Nogués S, Hodges M, Tcherkez GGB (2010) In folio isotopic tracing demonstrates that nitrogen assimilation into glutamate is mostly independent from current $\mathrm{CO}_{2}$ assimilation in illuminated leaves of Brassica napus. New Phytol 185:988-999

Gibon Y, Larher F (1997) Cycling assay for nicotinamide adenine dinucleotides: $\mathrm{NaCl}$ precipitation and ethanol solubilization of the reduced tetrazolium. Anal Biochem 251:153-157

Gibon Y, Blaesing OE, Hannemann J, Carrillo P, Hohne M, Hendriks JH, Palacios N, Cross J, Selbig J, Stitt M (2004) A Robot-based platform to measure multiple enzyme activities in Arabidopsis using a set of cycling assays: comparison of changes of enzyme activities and transcript levels during diurnal cycles and in prolonged darkness. Plant Cell 16:3304-3325

Hodges M (2002) Enzyme redundancy and the importance of 2oxoglutarate in plant ammonium assimilation. J Exp Bot 53:905916

Hodges M, Fleish V, Gálvez S, Bismuth E (2003) Higher plant NADP dependent isocitrate dehydrogenases, ammonium assimilation and NADPH production. Plant Physiol Biochem 41:577-585

Huege J, Sulpice R, Gibon Y, Lisec J, Koehl K, Kopka J (2007) GC-EI-TOF-MS analysis of in vivo carbon-partitioning into soluble metabolite pools of higher plants by monitoring isotope dilution after $\left(\mathrm{CO}_{2}\right)-\mathrm{C}-13$ labelling. Phytochemistry 68:22582272

Igamberdiev AU, Gardeström P (2003) Regulation of NAD- and NADP-dependent isocitrate dehydrogenases by reduction levels of pyridine nucleotides in mitochondria and cytosol of pea leaves. Biochim Biophys Acta 1606:117-125

Igamberdiev AU, Romanowska E, Gardeström P (2001) Photorespiratory flux and mitochondrial contribution to energy and redox balance of barley leaf protoplasts in the light and during lightdark transitions. J Plant Physiol 158:1325-1332

Isaacson T, Ohad I, Beyer P, Hirschberg J (2004) Analysis in vitro of the enzyme CRTISO establishes a poly-cis-carotenoid biosynthesis pathway in plants. Plant Physiol 136:4246-4255 
Karimi M, Inzé D, Depicker A (2002) GATEWAY vectors for Agrobacterium-mediated plant transformation. Trends Plant Sci 7:193-195

Kopka J, Schauer N, Krueger S, Birkemeyer C, Usadel B, Bergmuller E, Dormann P, Weckwerth W, Gibon Y, Stitt M, Willmitzer L, Fernie AR, Steinhauser D (2005) GMD@CSB.DB: the Golm Metabolome Database. Bioinformatics 21:1635-1638

Kruse A, Fieuw S, Heineke D, Müller-Röber B (1998) Antisense inhibition of cytosolic NADP-dependent isocitrate dehydrogenase in transgenic potato plants. Planta 205:82-91

Lancien M, Gadal P, Hodges M (2000) Enzyme redundancy and the importance of 2-oxoglutarate in higher plant ammonium assimilation. Plant Physiol 123:817-824

Landschütze V, Willmitzer L, Müller-Röber B (1995) Inhibition of flower formation by antisense repression of mitochondrial citrate synthase in transgenic potato plants leads to specific disintegration of the ovary tissues of flowers. EMBO J 14:660-666

Lemaitre T, Urbanczyk-Wochniak E, Flesch V, Bismuth E, Fernie AR, Hodges M (2007) NAD-dependent isocitrate dehydrogenase mutants of Arabidopsis suggest the enzyme is not limiting for nitrogen assimilation. Plant Physiol 144:1546-1558

Liu XJ, Prat S, Willmitzer L, Frommer WB (1999) Cis-regulatory elements directing tuber specific and sucrose inducible expression of a chimeric class I patatin promoter-GUS gene fusion. Mol Gen Genet 223:101-106

Nunes-Nesi A, Carrari F, Lytovchenko A, Smith AMO, EhlersLoureiro M, Ratcliffe RG, Sweetlove LJ, Fernie AR (2005) Enhanced photosynthetic performance and growth as a consequence of decreasing mitochondrial malate dehydrogenase activity in transgenic tomato plants. Plant Physiol 137:611-622

Nunes-Nesi A, Carrari F, Gibon Y, Sulpice R, Lytovchenko A, Fisahn J, Graham J, Ratcliffe RG, Sweetlove LJ, Fernie AR (2007) Deficiency of mitochondrial fumarase activity in tomato plants impairs photosynthesis via an effect on stomatal function. Plant $\mathbf{J}$ 50:1093-1106

Palomo J, Gallardo F, Suarez MF, Canovas FM (1998) Purification and characterization of $\mathrm{NADP}^{+}$-linked isocitrate dehydrogenase from Scots pine. Plant Physiol 118:617-626

Poolman MG, Miguet L, Sweetlove LJ, Fell DA (2009) A genomescale metabolic model of Arabidopsis and some of its properties. Plant Physiol 151:1570-1581

Pracharoenwattana I, Zhou W, Keech O, Francisco PB, Udomchalothorn T, Tschoep H, Stitt M, Gibon Y, Smith SM (2010) Arabidopsis has a cytosolic fumarase required for the massive allocation of photosynthate into fumaric acid and for rapid plant growth on high nitrogen. Plant J. doi:10.1111/j.1365-313X.2010.04189.x

R Development Core Team (2006) R: a language and environment for statistical computing. R Foundation for Statistical Computing, Vienna, Austria. ISBN 3-900051-07-0

Raghavendra AS, Padmasree K (2003) Beneficial interactions of mitochondrial metabolism with photosynthetic carbon assimilation. Trends Plant Sci 8:546-553

Robinson SA, Slade AP, Fox GG, Phillips R, Ratcliffe RG, Stewart GR (1991) The role of glutamate dehydrogenase in plant nitrogen metabolism. Plant Physiol 95:509-516

Roessner U, Luedemann A, Brust D, Fiehn O, Linke T, Willmitzer L, Fernie AR (2001) Metabolic profiling allows comprehensive phenotyping of genetically or environmentally modified plant systems. Plant Cell 13:11-29

Roessner-Tunali U, Hegemann B, Lytovchenko A, Carrari F, Bruedigam C, Granot D, Fernie AR (2003) Metabolic profiling of transgenic tomato plants overexpressing hexokinase reveals that the influence of hexose phosphorylation diminishes during fruit development. Plant Physiol 133:84-99

Schaarschmidt S, Roitsch T, Hause B (2006) Arbuscular mycorrhiza induces gene expression of the apoplastic invertase LIN6 in tomato (Lycopersicon esculentum) roots. J Exp Bot 57:40154023

Schauer N, Steinhauser D, Strelkov S, Schomburg D, Allison G, Moritz T, Lundgren K, Roessmer-Tunali U, Forbes MG, Willmitzer L, Fernie AR, Kopka J (2005) GC-MS libraries for the rapid identification of metabolites in complex biological samples. FEBS Lett 579:1332-1337

Scheibe R (2004) Malate valves to balance cellular energy balance. Physiol Plant 120:21-26

Scheibe R, Stitt M (1988) Comparison of NADP-malate dehydrogenase activation QA reduction and $\mathrm{O}_{2}$ evolution in spinach leaves. Plant Physiol Biochem 26:473-481

Scheible WR, Gonzalez-Fontes A, Lauerer M, Müller-Röber B, Caboche M, Stitt M (1997) Nitrate acts as a signal to induce organic acid metabolism and represses starch metabolism in tobacco. Plant Cell 9:783-798

Scheible WR, Krapp A, Stitt M (2000) Reciprocal diurnal changes of phosphoenolpyruvate and NADP-isocitrate dehydrogenase expression regulate organic acid metabolism during nitrate assimilation in tobacco leaves. Plant Cell Environ 23:11551167

Schneidereit J, Häusler RE, Fiene G, Kaiser WM, Weber APM (2006) Antisense repression reveals a crucial role of the plastidic 2oxoglutarate/malate translocator DiT1 at the interface between carbon and nitrogen metabolism. Plant J 45:206-224

Siedow JN, Day DA (2000) Respiration and photorespiration. In: Buchanan B, Gruissem W, Jones R (eds) Biochemistry and molecular biology of plants. American Society of Plant Physiologists, Rockville, pp 676-728

Sienkiewicz-Porzucek A, Nunes-Nesi A, Sulpice R, Lisec J, Centeno DC, Carillo P, Leisse A, Urbanczyk-Wochniak E, Fernie AR (2008) Mild reductions in mitochondrial citrate synthase activity result in a compromised nitrate assimilation and reduced leaf pigmentation but have no effect on photosynthetic performance or growth. Plant Physiol 147:115-127

Sienkiewicz-Porzucek A, Sulpice R, Osorio O, Krahnert I, Leisse A, Urbanczyk-Wochniak E, Hodges M, Fernie AR, Nunes-Nesi A (2010) Mild reductions in mitochondrial NAD-dependent isocitrate dehydrogenase activity result in altered nitrate assimilation and pigmentation but do not impact growth. Mol Plant 3:156173

Studart-Guimarães C, Fait A, Nunes-Nesi A, Carrari F, Usadel B, Fernie AR (2007) Reduced expression of succinyl CoA ligase can be compensated for by an upregulation of the $\gamma$-aminobutyrate (GABA) shunt in illuminated tomato leaves. Plant Physiol 145:626-639

Sweetlove LJ, Lytovchenko A, Morgan M, Nunes-Nesi A, Taylor NL, Baxter CJ, Eickmeier I, Fernie AR (2006) Mitochondrial uncoupling protein is required for efficient photosynthesis. Proc Natl Acad Sci USA 103:19587-19592

Sweetlove LJ, Beard KFM, Nunes-Nesi A, Fernie AR, Ratcliffe RG (2010) Not just a circle: flux modes in the plant TCA cycle. Trends Plant Sci (in press)

Tauberger E, Fernie AR, Emmermann M, Renz A, Kossmann J, Willmitzer L, Trethewey RN (2000) Antisense inhibition of plastidial phosphoglucomutase provides compelling evidence that potato tuber amyloplasts import carbon from the cytosol in the form of glucose 6-phosphate. Plant J 23:43-53

Tcherkez G, Mahé A, Gauthier P, Mauve C, Gout E, Bligny R, Cornic $G$, Hodges $M$ (2009) In folio respiratory fluxomics revealed by ${ }^{13} \mathrm{C}$-isotopic labeling and H/D isotope effects highlight the noncyclic nature of the tricarboxylic acid "cycle" in illuminated leaves. Plant Physiol 151:620-630

Tercé-Laforgue T, Dubois F, Ferrario-Mery S, Pou de Crecenzo MA, Sangwan R, Hirel B (2004) Glutamate dehydrogenase of tobacco is mainly induced in the cytosol of phloem companion cells 
when ammonia is provided either externally or released during photorespiration. Plant Physiol 136:4308-4317

Urbanczyk-Wochniak E, Baxter C, Kolbe A, Kopka J, Sweetlove LJ, Fernie AR (2005) Profiling of diurnal patterns of metabolite and transcript abundance in potato (Solanum tuberosum) leaves. Planta 221:891-903

Wang S, Liu J, Feng Y, Niu X, Giovannoni J, Liu Y (2008) Altered plastid levels and potential for improved fruit nutrient content by downregulation of the tomato DDB1-interacting protein CUL4. Plant J 55:89-103

Wigge B, Krömer S, Gardeström P (1993) The redox levels and subcellular distribution of pyridine nucleotides in illuminated barley leaf protoplasts studied by rapid fractionation. Physiol Plant 88:10-18

Zanor MI, Osorio S, Nunes-Nesi A, Carrari F, Lohse M, Usadel B, Kuhn C, Bleiss W, Giavalisco P, Willmitzer L, Sulpice R, Zhou YH, Fernie AR (2009) RNA interference of LIN5 in Solanum lycopersicum confirms its role in controlling Brix content, uncovers the influence of sugars on the levels of fruit hormones and demonstrates the importance of sucrose cleavage for normal fruit development and fertility. Plant Physiol 150:1204-1218 